\title{
Un poeta virreinal peruano: Fray Francisco del Castillo, "el Ciego de la Merced"
}

FRAY Francisco del Castillo, apodado "el Ciego de la Merced", vivió en Lima entre 1716 y 1770 . Personaje de biografía legendaria fundamentada en su ceguera, rara inteligencia, dotes como repentistá y como escritor "de pensado", a ella contribuyó Ricardo Palma en sus célebres tradiciones, ${ }^{1}$ al igual que sucedió con otras figuras de la Lima virreinal. La mayor parte de los datos históricos que conocemos de él son los que aportó Guillermo Lohmann Villena en El arte dramático en Lima durante el virreinato. ${ }^{2}$

Castillo dejó escrita una obra abundante. De él se conservan cinco piezas dramáticas extensas y siete breves y más de un centener de composiciones líricas, amén de otros tantos poemas que se le atribuyen, muchos de los cuales permanecen inéditos. ${ }^{3}$

1 "El Ciego de la Merced"; en Apéndice a mis ultimas tradiciones peruanas, Barcelona, Maucci, [1910], pp. 269-280; "Un Calembourg" y "Otra improvisación del Ciego de la Merced", en Tradiciones en salsa verde, Lima, ediciones de la Biblioteca Universitaria, imp. Artes Gráficas de Editorial Jurídica, 1973, pp. 31-33 y 34.

2 Publicaciones de la Escuela de Estudios Hispano-Americanos de la Universidad de Sevilla: XII, serie 2a., monografia 3, Madrid, CSIC, 1945, pp. 413-425. También han estudiado a Castillo, Severo Aparicio en "Vida y obra poética del Ciego de la Merced de Lima", separata de la Revista de Estudios de Madrid, año XVII, núm. 54, julio-septienubre de 1961; pp. 457-479, y Carlos Milla Batres en Vida y obra literaria edita e inédita del Ciego de la Merced: Fray Francisco del Castillo Andraca y Tamayo (1716-1770), tesis doctoral, Lima, UNMSM, 1976. La principal edición impresa del Ciego de la Merced es Obras de Fray Francisco del Castillo, edición de Rubén Vargas Ugarte, colección "Clásicos peruanos", vol. 2, Lima. Studium, 1948. En junio de 1987 el profesor Daniel R. Reedy, de la Universidad de Kentucky, me comento que próximamente iba a publicar un artículo sobre Castillo. No obstante estos trabajos, el Ciego de la Merced sigue siendo un escritor virreinal mal conocido, en cuyos estudios pesan todavia mucho las tradiciones de Palma.

3 Para el estado de la cuestión puede verse mi "Relación completa de las 
Tuvo como mecenas a José Perfecto de Salas, asesor del virrey Amat en Perú, quien al parecer dispuso las obras del Ciego para su edición, que no se llevó a cabo entonces por diversas dificultades. ${ }^{4}$ En Castillo no sólo sobresale el número de sus obras, sino también su calidad, que permiten considerarlo uno de los mejores escritores virreinales hispanoamericanos. Yo me he ocupado de la edición y del análisis literario de todo su teatro ${ }^{5}$ y en este artículo deseo dar a conocer algunos poemas suyos como botón de muestra de su obra.

Como poeta lírico Castillo puede ser calificado de rococó. ${ }^{6}$ Es un poeta que gusta de lo menudo, del juego, de la galantería; se complace en mencionar objetos ornamentales y elude, en general, temas profundos. Su lenguaje es más sencillo que el del pleno barroco y el despliegue de ingenio va acompañado de humor. Los poemas que recojo en este artículo son inéditos ${ }^{7}$ y dan a conocer diversas facetas de la personalidad y la obra del Ciego: su afición a los toros y a lo popular, su comicidad, su inspiración religiosa, su habilidad como improvisador y su actitud como cortesano que adula al mecenas. Aunque algunos de ellos sean puestos en boca de otros personajes, es claro que pertenecen a Castillo, salvo la "Sentencia". En las normas de transcripción sigo las adoptadas por mí para la edición de su teatro, donde destaca que conservo el seseo y su correspondiente ultracorrección.

\section{Concepción Reverte}

obras de Fray Francisco del Castillo (Lima, 1716-1770)", Rilce, Universidad de Navarra, 1987, en prensa.

4 Làs características de los manuscritos conservados con las obras de Castillo parecen indicar que fueron preparados para una próxima impresión. Entre los óbices que la impidieron destaca el rompimiento entre Amat y su asesor, con la partida de Salas de Lima en 1775.

5 El análisis literario está publicado como Aproximación crítica a un dramaturgo virreinal peruano: Fray Francisco del Castillo ("el Ciego de la Merced"), Cádiz, Servicio de Publicaciones de la Universidad, 1985. Mi edición de su teatro se encuentra en microfichas en espera de su posible comercialización.

6 Aunque el término deba ser mucho más estudiado respecto a toda la lírica virreinal hispanoamericana y al Ciego de la Merced en particular, a la vista de la mayor parte de su obra poética no es aventurado utilizarlo.

7 Todos pertenecen al vol. 805, Fondo Varios, Archivo Nacional de Santiago de Chile. Los poemas ocupan las pp. 31-39, 61-65, 81-84. 
Al Señor Doctor Don Juan José Vidal, Agente del Real Fisco, la abuela de la Tinajita le escribía

\section{Romance}

Una de aquellas andantes del uno al otro portal, que por tan caritativas paran en la Caridad

5 y que con gustos ha hecho dos mil incautos quejar, porque con hacerles bien les hizo infinito mal; en la Corrida de Toros

10 de este año, al acabar, decía sin conformarse en esta conformidad: [¿Pos] ible es que una mujer que se hizo tanto lugar

15 que exedía a los comunes de cualquier comunidad, se vea tan destituida, no teniendo en qué sentar de estas sus asentaderas

20 ni siquiera la mitad?; ¿aquélla que con sus cuartos feriaba sin limitar hoy ni una cuarta de cuarto se le presente en su edad?;

25 caquélla que supo a muchas cofradías arrostrar, hoy, sola, sin tener otra que la de su soledad?; ¿la que con ser carta doble

30 tanto se llegó a franquear que no ha tenido otro porte que la liberalidad?;

5 Gustos: corregido sobre gastos.

15 Los: corregido sobre las.

26 Arrostrar: corregido sobre arrastrar. 
¿a la que con galerías

solían antes rogar,

35 hoy ni galeras le ofrecen

por ser obra de piedad?

$Y$ aunque estos motivos son

bastantes a deslomar

a una que entre desolladas

40 no fuese la capital,

hay otro más poderoso

que me hace desesperar,

$y$, a tener juicio, perdiera

gran parte de su entidad:

45 Este se reduce a que

he venido a averiguar

que, a quien quijadas no tiene, muchas muelas se le dan;

a un sujeto conocido

50 ciego de natividad,

cuarto porque vea ioros

le acaban de preparar.

¿Quién habrá visto en el mundo más monstruosa necedad?

55 iCiego en Toros!, imás implica que un mudo con predicar!;

pues de esta suerte a tullidos

los sacarán a danzar, los cojos correrán posta

60 y los sordos cantarán; porque, digan lo que quieran, no alcansa la habilidad, al correr, sin pies ni manos, como ni a ver sin mirar.

$65 \mathrm{Y}$, en fín, conociendo él mismo tan enorme impropiedad, se llevó a su Esteban por si lo quisiesen apedrear. No es el ciego a quien se debe

70 muy muchas piedras tirar, sino al que esconde la mano pero no la iniquidad.

Desproporción que da en rostro 
y nadie puede arrostrar,

75 que se llene un gran vacío con la misma vaciedad.

A él, sin tenerlos, dio en ojos tanto aquella ociocidad, que por ocuparla quiso

80 ciertos huecos alquilar; con razón, que para ver tan solemne novedad, cosa es de alquilar balcones por reír y por admirar.

85 A describir las Corridas disque vino, y es verdad, que están las vistas corridas de verse así despreciar; como estuvieran corridas

90 las manos, si es que a pintar estas Corridas de Toros traen al manquito Tomás. Por esa razón a ti, insigne Agente Fiscal,

95 como a centro de las vistas ocurren a tu piedad, por si logran conseguir las quieras desagraviar de esta irónica figurà

100 formada en la ceguedad; porque si en tiempo no estorbas esta loca impropiedad, la Semana Santa en andas también lo querrán sacar.

105 Permítase norabuena, que puedá el cuarto arrendar, que así las botillerías tendrán su comodidad. Así lo pide y suplica

110 una que en su mocedad cegó, y hoy tiene los ojos abiertos de par en par. 
Respuesta a la demanda de la abuela de la Tinajita

\section{Romance}

Mujer, que cuando eras mosa

fuiste capás de dejar

con deseo de aprender

a la misma iniquidad;

5 puerta franca para todos

con tal liberalidad, que eran en ti más baratas las ferias que en el portal;

abuela de una Tinaja

10 en donde se puede hallar, en lugar de agua estilada asufre de liviandad:

Ya que piensas querellarte y me vienes a buscar,

15 llevarás palo de siego, que bien merecido va.

Toda tu rabia proviene de que a los Toros no vas, y si tienes tantos cuernos

20 ¿dónde hay para otros lugar?

Solamente a tu ignorancia puede hacerle novedad que un siego supla el defecto con la vista intelectual;

25 digo esto, porque te pones neciamente a murmurar el que yo vaya a los Toros cuando en mí vista no hay. Mucho pudiera decirte

30 sobre esta dificultad, pero tú entiendes el libro de generación nomás; algo te diré, no obstante, porque el Agente Fiscal

35 diga en vista que, aunque siego, no me falta claridad.

En un vidrio graduado, 
el que quisiere verá, que sus mismos grados hacen

40 de aquello que es menos más; lo mismo a ti te sucede, porque, en llegando a mirar en Toros al que no ve, se figura en propiedad;

45 pero si tú especularas la razón de esto en qué está, no hicieras sólo al centido criterio de la verdad. Esta diverción no sólo

50 recreo a la vista da, cada sentido en su línea algo tiene que gosar:

Lo que entra por el oído placer previniendo va,

55 que en el tímpano las voces armonía han de causar. Flora y Vertumno en la Plasa un vergel formando están, y lo que da en las narices,

60 si no es tú, no huele mal. Ir allá para escribir no lo jusgo impropiedad, pues lo que no oyen los ojos los oídos lo verán.

65 Llevo a Esteban porque oiga especies que he de cantar, porque ellas, a darme asunto, seguras con éste van.

¿No será mayor mi triunfo

70 cuando en la posteridad se oiga que acerté a escribir lo que no pude mirar? Si supieras tú que es numen quien me entró en proyecto tal,

75 advirtieras dicipada

57 Vertumno: divinidad romana que presidía el cambio de las estaciones. 
en su luz mi ceguedad, y así puedes creer, simplona, que yo no soy siego ya, porque, transformado en él,

80 todo es en mí claridad.

Tales son las instrucciones con que ilustrándome está, que más comprendo en su idea que en la vista material;

85 porque sin mérito mío le debo fineza tal, que se hace ojos porque yo salga de un torpe ignorar. Que alquile mi cuarto dices,

90 y eso tú mejor lo harás, porque de alquilar los tuyos tu fábrica es hueso ya.

Dices que en Semana Santa en andas me sacarán,

95 y yo temo que en la Pascua tú coma Judas saldrás.

Por tanto, pido y suplico a nuestro Agente Fiscal, que con pedir que te maten

100 me dé la vida Vidal, otrosí digo, Señor, que si la ven con piedad, la envíen a Juan Fernández si está capaz de poblar,

$105 \mathrm{y}$, quitado este embaraso, Usía decir podrá:

Corra la vista y el siego escriba de Toros más. También pide el suplicante

110 despacho con brevedad, porque si se cierra el punto no habrá línea que tirar. 


\section{Muy poderoso Señor}

El Agente del Real Fisco, de aqueste expediente en vista que, aunque en romance está puesto, echa verbos como chispas;

5 donde por falta de agua se queja la Tinajita, quien de las muchas mojadas seca está de humedecida; por la boca de su abuela

10 su querella formalisa, cogiendo de aguas arriba toda su genealogía.

De que nadie le dé un cuarto sus sentimientos duplica,

15 cuando ella a muchos urgentes les dio piadosa acogida. De verse a un siego pospuesta su angustia a voces intima, la que tuvo en los concursos

20 el grado de preferida. Que a un siego lleven a Toros llora, triste y afligida, y que hoy nadie pueda ver a la que fue tan bien vista.

25 Que sin tener ojos vayan de Toros a la Corrida, funda por diversos medios que contradicción implica; mas su antigua sequedad

30 aun la reflexión le quita para advertir que los siegos también por los oídos miran, y que los sinco sentidos, con conexión peregrina,

35 unos en subcidio de otros sus oficios ejersitan. Cuanto ella por dadivosa

32 Oidos: antes ojos (tachado). 
desperdició en torerías, un siego, honor de su Patria,

40 en memorias eternisa.

La posteridad verá, cuando sus obras se impriman, que cada rasgo en su pluma fue una octava maravilla;

45 verá que su gran talento atesoró en pocos días más caudal que el que ha arrojado el Potosí de sus minas; verá que el ponerlo en andas

50 era acción justa y debida a un hombre que en proceción merese andar por su dicha, porque del todo ha dejado guaragua y botillerías

55 por recibir agasajos de quien lo aprecia y estima. Si acaso, por real y medio, el que le dan cuarto alquila, es porque todos conoscan

60 quien está en la galería. Dise que muy muchas piedras deben llover desprendidas sobre quien la mano esconde y descubre su malisia;

65 mas yo jusgo que la pobre está rabiando de envidia, porque ella no tiene mano que le mueva la Picina; para el siego, este es el ángel

70 que sus pasos ilumina, $\mathrm{y}$, haciéndolo inteligencia, genio es que lo inmortaliza. Que oiga el que no sea sordo, que quien tiene pies aprisa

75 ande y el que no sea mudo cante con dulce armonía,

58 Alquila: tachado -n. 
cosa es que, por muy común, como la ven no la admiran; mas que un siego lo vea todo,

80 cuasi es una obra divina, y es que un Argos vigilante que, amante, la ciudad mira, porque sus grandezaz cante le da a ese siego sus niñas.

85 Qué importa, pues, que, angustiada, en tanta soledad gima quien, porque enterró sus muertos, quebró con la cofradía; al recibir las limosnas

90 que los hermanos le envían, para dar cuenta con pago ya con su fiador se obliga. Cuanto aquélla por sus obras se llora tan abatida,

95 tanto este otro por sus poemas sobre muchos se autorisa. Por todo esto es de sentir el Agente que hoy Usía a relegación condene

100 a la infeliz Tinajita, y que el siego y bachiller en sus tareas prosigan porque la Fiesta de Toros quede perfecta y concluida.

105 Mas, pues es tiempo de gracias, justo es que el Agente pida que, a quien confiesa sus yerros, se le absuelva de justicia; sobre todo mandará

110 su recta distributiva hoy, tres de enero, del año de sesenta y nueve en Lima.

88 Quebró: antes acabó (tachado), posteriormente se agregó con (escrito encima). 


\section{Sentencia}

Fallo, atento los autos, con audiencia del Fisco y de las partes mala y sana, que debo pronunciar de buena gana en la forma siguiente mi sentencia:

$5 \quad$ La que su vida larga y su insolencia en hacer toros consumió, losana, no será de razón también que, ufana, al desaserlos tenga concurrencia;

pero el ciego (mal digo), la lumbrera, 10 del Pindo cisne de las Indias lauro, Zodíaco felíz de primavera,

ni en los signos materia dé al reparo; por Géminis es justo que a su esfera le sostituya duplicado Tauro.

6, 8, 13, 14 Subrayados según el manuscrito.

11 Tachado y el a comienzo del verso. 
En nombre de un miserable a quien se le trata un casamiento, responde el poeta excusándose de dar cuanto le pidiere la novia en estas

seguidillas

Han dado en que me case con cierta niña yo digo que la tomo como no pida,

5 porque, en pidiendo, seré de la tenaza el caballero.

Mas, por si es petulante, quiero avisarla

10 lo que he de concederla que ha de ser nada, que, en sabiendo esto, claro está que por nada no ha de haber pleito.

15 Iréme figurando lo que me pide, que aquí nada se pierde pues no se exhibe, y es bien pensado,

20 por lo que sucediere, que esté contado.

Si quiere casa grande le digo luego:

Para eso, vida mía,

25 vete a un convento, porque es muy cierto que, aunque quieras fundirme, ni un cuarto tengo.

Cuando me pides clavos

30 es la respuesta:

Adonde no hay un cuarto ¿cómo habrá piesas?,

$6 \mathrm{Al}$ acabar la línea tachado: el caballero.

27 Quieras fundirme: antes (tachado) me despe [incompleto]. 
ni es bien que tengas a quien pueda matarte

35 o morir pueda.

En pidiéndome coche le digo: Paso, que cosa que yo estimo no anda rodando,

40 y fuera injuria poner hoy una discreta entre dos mulas.

Si tostada me pide diré con rabia:

45 ¿Cómo tan sin empacho pides tostada?, ¿no ves que a Midas le fue veneno el oro en la barriga?

50 En nombrándome puntas diré que calle, pensando que las pide para clavarme,

diciendo: iMi alma,

55 sólo las Amasonas son Capitanas!

En boqueándome encajes así le digo:

Tuyo me ofresco entero

60 mas no partido, y tu belleza no ha menester, Señora, que la guarnescas.

En pidiendo manillas

65 de oro muy fino sabrá que el castellano no lo he entendido, y así es presiso poner muchas escalas

70 por lo subido.

En queriendo sarcillos diré enfadado: ¿Tus orejas son puertas 
para candados?,

75 y es gran martirio

no desembarasarse

de los sarcillos.

Si pide faldellines

hará mal ella,

80 pues por no ir a sacarlos

habrá contienda,

$y$ es mucho lance

que por un sastre quiera

ver un desastre.

85 Medias no ha de ponerse,

aunque se enfade,

que no quiero crecientes,

menos menguantes,

y no es seguro

90 que ande una mujer noble

buscando puntos.

Si me pidiere ligas

le haré que vea

que ya nos ha ligado

95. la Madre Iglesia,

y haré notorios

los lazos que nos juntan

del matrimonio.

Para que no me pida

100 jamás sapatos

le diré las virtudes

de los descalsos,

pues es bien claro

que ellos sin sapateros

105 son ajustados.

Porque espejos no pida

y mejor vea,

el espejo de ejemplos

le haré que lea,

110 pues verá claros, no por entre vidrieras,

los desengaños.

Si guardar estas leyes

113 Guardar: tachado -e. 
quiere mi niña,

115 aquí tiene mi mano

pero vacía,

y es de estimarla, porque yo se la entrego con toda el alma.

Haciendo relación del inefable misterio de la Encarnación del Hijo de Dios, dijo el autor las siguientes

$$
\text { quintillas. }
$$

Hoy, con toda claridad, una historia contaré; negarla será impiedad, porque de su Autor yo sé

5 que Él es la misma verdad.

Con su mujer lisonjero dejó Adán perdido el mundo, y Dios, con amante esmero, nos envió un Adán segundo,

10 que existió antes del primero.

A su Hijo mismo nos dio; mas yo de esta acción colijo lo mucho que nos amó, y cuenta que el que esto dijo

15 el Evangelio escribió.

El decreto prevenía darle al Verbo humano ser, porque sin Dios no podía el hombre satisfacer

20 deudas que con Dios tenía. A una Virgen preservada le dio por Madre escogida, en tanto grado elevada que ser no pudo exedida

25 si no es del que fue criada.

Diole a ésta esposo, el Señor,

116 Abajo de esta línea se empezó a escribir Des, luego tachado. 
con quien en castidad viva, y fue trasa de su amor para que no se conciba deshonra el más alto honor.

María y José nombrados son los consortes queridos, de suerte a Dios entregados, que viviendo en Él unidos entre sí están más separados.

Sucedió que sierto día, estado ella retirada donde su oración hacía, de un Arcángel saludada

40 se halló en un Ave María.

De gracia, dice, llena eres, el Señor contigo mora, ioh, Templo de sus placeres! y por Él eres, Señora,

45 bendita entre las mujeres.

Dejó turbada a María lo que el Arcángel hablaba y en su turbación mostraba que el elogio le venía

50 porque ella no lo esperaba.

Nada (prosigue) es temible para ti, pues el Señor, gracia hallaste en el amor, con la que no es compatible

55 tal género de temor.

Que un Hijo tendrás es fijo y Jesús se llamará; por grande se admirará y, del Altísimo Hijo,

60 Él mismo se nombrará.

Por ser Hijo de tal Madre, de Jacob en la manción, con derecho y con razón tendrá de David, su Padre

65 el asunto y poseción.

Con quietud inalterable felizmente reinará 
este Monarca inefable, y su Reino acabará con la vida perdurable.

La Virgen con suspención dijo: Para tal efecto no halla causa mi razón y el no alcanzar el concepto es porque ignoro varón.

En esto daba a entender María, al Eterno Padre, que no pensaba perder por el honor de ser Madre,

80 de Virgen el puro ser.

Todo lo serás, le dice el celeste embajador; el Espíritu de amor vendrá sobre ti, felice,

85 y sombra te hará el Señor.

Sólo Dios causa ha de ser del prodigio que ha de obrar, por eso el que ha de nacer de ti su Hijo ha de llamarse,

90 ni otro padre ha de tener.

Isabel ha concebido aun en su esterilidad, ya seis meses han corrido, que al poder de la Deidad

95 ningún imposible ha habido.

A esto dice: Veisme aquí, la Esclava soy del Señor, y pues que para Él nací, aunque indigna del favor

100 su voluntad se haga en mí.

María, desde este instante, fue la verdadera Atlante, mereciendo, desde el suelo, del que no cabe en el cielo

105 ser dichosa sustentante. 
Dando el autor a su querido mesenas, que era un Señor Ministro, noticia de una fluxión catarral que padeció, le cantó respentinamente ${ }^{*} \mathrm{al}^{* *}$ son de una vihuela las siguientes

$$
\text { quintillas. }
$$

Ya, Señor idolatrado, que libre de mi dolencia volver a verte he logrado, cantaré con complacencia

5 lo que antes había llorado: Una fluxión catarral, cruel, de mí se apoderó, y es cierto, Señor Fiscal, que en mí se acrecentó el mal

10 porque en ti el bien ne faltó.

El lunes por la mañana la guerra me vino a hacer esta enfermedad tirana, sin poderme defender,

15 por no tener parte sana.

A mi cabeza un fatal tormento oprimió, de suerte, que a juzgar llegué, y no mal, que fuese pena de muerte

20 viendo que era capital.

Preliminar del dolor fue para mi cuerpo un frío, pero no para mi amor porque antes le dio el resfrío

25 nueva materia al ardor.

Sólo el pecho esta opresión no la padeció, y sospecho cuál fue de esto la razón, y es que tú en mi corazón

30 serviste de escudo al pecho.

Cuando reflexión hacía

* Respentinamente: sic.

** En el manuscrito repetido al por error. 
de que a tu lado no estaba, tanto mi dolor crecía, que sin sentir me quedaba

35 de lo mucho que sentía.

Mi designio era buscarte en medio de mal tan fuerte, pero, temiendo la muerte, imaginé que el hallarte

40 fuese el medio de perderte.

Para el restablecimiento la quietud se me intimaba, pero era vano el intento que fuera del centro estaba

45 en continuo movimiento.

Tomé harta ropa conmigo a fin de lograr sudor, pero con verdad te digo que sin tu abrigo, Señor,

50 es inútil todo abrigo.

Vínoseme al pensamiento si dudabas mi aflicción, mas yo dije no al momento, que quien sabe mi pación,

55 no ha de ignorar lo que ciento.

Ya, en fin, puedo respirar, ya sé que puedo vivir, $y$ así te vine a buscar por poder asegurar

60 lo que llegué a colegir.

Y pues he cobrado aliento, yo quiero que en tu presencia mi salud vaya en aumento, pues ya declaró la ausencia

65 ser alma de mi tormento.

A mi mal ya no resisto si me volviera a invadir, porque se ha hecho tan bien qu[isto] que lo volviera a sufrir

70 sólo por haberte visto. 